\title{
¿Qué Hemos Aprendido sobre la Radiodifusión de Servicio Público en el Mundo? Una Revisión Sistemática de la Literatura y Sugerencias para Investigaciones Futuras
}

\section{What Have We Learned about Public Service Broadcasting in the World? A Systematic Literature Review and Suggestions for Future Research}

Tania Lestón-Huerta, Universidad Carlos III. España.

tanialh96@gmail.com

$[\mathrm{CV}]$ (0)

Manuel Goyanes, Universidad Carlos III. España.

mgoyanes@hum.uc3m.es

[CV] (c) G

Barbara Mazza ${ }^{1}$, Sapienza, Universidad de Roma. Italia.

barbara.mazza@uniroma1.it

$[\underline{\mathrm{CV}}]$ (1) $\mathrm{R}^{\mathrm{C}}$

Este artículo está financiado con fondos del proyecto «Nuevos valores, gobernanza, financiación y servicios audiovisuales públicos para la sociedad de Internet: con trastes europeos y españoles» (RTI2018-096065-B-I00) del Programa Estatal de España de I+D+I orientado a los Retos de la Sociedad del Ministerio de Ciencia e Innovación del Gobierno de España /AEI/FEDER.

Cómo citar este artículo / Referencia normalizada

Lestón-Huerta, T., Goyanes, M. y Mazza B. (2021). ¿Qué hemos aprendido sobre la Radiodifusión de Servicio Público en el Mundo? Una Revisión Sistemática de la Literatura y Sugerencias para Investigaciones Futuras. Revista Latina de Comunicación Social, 79, 65-88. https://www.doi.org/10.4185/RLCS-2020-1489

\section{RESUMEN}

Este estudio ofrece una revisión de la literatura publicada sobre Radiodifusión de Servicio Público (RSP) entre los años 2009 y 2019. En total, se obtuvieron 232 artículos tras una búsqueda bibliográfica en cinco bases de datos (Scopus, Web of Science Core Collection, ProQuest, Academic Search

\footnotetext{
${ }^{1}$ Autor para correspondencia: Barbara Mazza, Departamento de Comunicación e Investigación Social, vía Salaria 113, 00198 Roma, Italia.
} 
Ultimate y Google Scholar), de los cuales setenta y ocho se consideraron relevantes, según los criterios del estudio. El artículo resume los objetos de estudio, los escenarios bajo análisis, los enfoques metodológicos y los principales patrones temáticos de las investigaciones existentes, proporcionando una evaluación crítica de los principales hallazgos y direcciones de las investigaciones. Sobre la base de este resumen temático, el estudio ofrece sugerencias sobre cómo avanzar e identificar algunos de los principales desafíos y limitaciones en esta área de investigación.

PALABRAS CLAVE: RSP, Radiodifusión de Servicio Público, revisión de literatura, regulación de medios, medios digitales, interés público.

\begin{abstract}
This study provides a review of the literature published on Public Service Broadcasting (PSB) between the years 2009 and 2019. In total, 232 articles were obtained following a literature search of five databases (Scopus, Web of Science Core Collection, ProQuest, Academic Search Ultimate, and Google Scholar), of which seventy-eight were deemed relevant, based on the study criteria. The article summarizes the objects of study, settings under analysis, methodological approaches, and principal thematic patterns of extant research, providing a critical assessment of the main findings and research directions. Based on this thematic summary, the study offers suggestions on how to move forward and identify some of the main challenges and limitations on this area of inquiry.
\end{abstract}

KEYWORDS: PBS, Public Service Broadcasting, literature review, media regulation, digital media, public interest.

\title{
CONTENIDO
}

1. Introducción. 2. Método. 2.1. Procedimiento de búsqueda de bibliografía y bases de datos. 2.2. Selección de títulos y resúmenes. 2.3 Síntesis y análisis. 3. Resultados. 3.1. Digitalización y Nuevas tecnologías. 3.2. Modelo de negocio y financiación. 3.3. Políticas y regulación. 3.4. Valor público e interés ciudadano. 4. Estudios de RSP: limitaciones e investigaciones futuras. 4.1. Proporcionar posibles estrategias para enfrentar los desafíos de la RSP. 4.2. Calidad y características de los programas públicos. 4.3. Gestión de redes sociales en diferentes contextos. 4.4 Mejora del análisis cultural y artístico. 5. Conclusiones. 6. Referencias.

Traducción por Paula González (Universidad Católica Andrés Bello, Venezuela)

\section{Introducción}

Los organismos de radiodifusión de servicio público (RSP), comúnmente conocidos por el acrónimo en inglés de PSB, son entidades públicas cuya misión tradicional es proporcionar un servicio de medios de comunicación universal y democrático (Harrison y Woods 2001). La RSP se considera un pilar fundamental de las sociedades democráticas (Jacobs, Meeusen y D'Haenens 2016) — principalmente en Europa, donde su papel "parece, sin embargo, más amplio que el puramente político" (Harrison y Woods, 2001, 480) - ya que también abarca funciones educativas, sociales y culturales. Desde sus orígenes, la RSP ha sido fundamental para fomentar los valores públicos y cívicos, garantizar el acceso de los ciudadanos a información verificada (Scannell 2005) y preservar la cultura común y el bienestar de las sociedades (Ibarra \& Nord 2014; Jõesaar 2011; Scannell 2005; Suárez- Candel 2011).

Sin embargo, en los últimos años, el papel tradicional de la RSP ha sido cuestionado debido a los crecientes desafíos relacionados con sus dificultades de financiación (Arriaza Ibarra 2013; Collins 2011; Herzog \& Karppinen 2014; Huntsberger 2014; Jõesaar 2011), la creciente competencia del 
mercado (Brink Lund y Edelvold Berg 2009; Dawes 2014; Donders 2010; García de Madariaga, Lamuedra Graván y Tucho Fernández 2013; Johnson 2013), y nuevas tecnologías y plataformas digitales (Debrett 2009; Ejbye Sørensen 2013; Kant 2014; Sjøvaag, Stavelin y Moe 2015; Schwarz 2016) que han interrumpido sus operaciones comerciales de larga data. En este contexto turbulento, la situación de los medios públicos ha instado a los organismos de radiodifusión y a los gobiernos a repensar las estrategias comerciales y la producción de contenido de RSP para preservar los derechos e intereses de los ciudadanos (Ginosar y Krispil 2015; Iosifidis 2011; Sjøvaag, Pedersen y Owren 2019; Van Dijck y Poell 2015).

A pesar del relevante papel de la RSP en el fomento de valores importantes (como el pluralismo o la diversidad) en las sociedades democráticas, se ha prestado poca atención a los posibles grupos de investigación que componen esta importante literatura. Argumentamos que una revisión sistemática de los estudios sobre el rol y las funciones de la RSP es esencial por varias razones. Primero, dado que la atención académica sobre la RSP ha crecido exponencialmente en los últimos años debido a transformaciones digitales y organizacionales claves (D'Arma 2018; Donders, Van den Bulck y Raats 2019; Evans 2018; Keinonen y Klein Shagrir 2017; Värk y Kinds 2019), existe una creciente presión para sistematizar y proporcionar una visión holística de los principales hallazgos y corrientes de investigación. En segundo lugar, dadas las diferentes comunidades de investigación interesadas en ilustrar y problematizar los principales desafíos sociales, políticos y económicos de la RSP, existe una creciente necesidad de escudriñar sus tradiciones de investigación y proporcionar nuevas vías de investigación que aborden las brechas metodológicas y temáticas que actualmente se pasan por alto. Este estudio tiene como objetivo abordar estas lagunas de investigación proporcionando una descripción general del estado actual de desarrollo de la investigación de la RSP en el campo de la comunicación. Por último, se espera que este estudio contribuya a futuras investigaciones en este dominio.

\section{Método}

\subsection{Procedimiento de búsqueda de bibliografía y bases de datos}

Los artículos analizados en esta revisión de la literatura se han recopilado mediante una búsqueda sistemática en cinco bases de datos diferentes y siguiendo las pautas de PRISMA, que se establecieron para recuperar artículos relevantes y "mejorar la transparencia, precisión, integridad y frecuencia de la revisión sistemática documentada y protocolos de meta-análisis" (Shamseer et al. 2015, 1). La búsqueda bibliográfica se realizó en octubre de 2019 utilizando las siguientes bases de datos: Scopus, Academic Search Ultimate, ProQuest, Web of Science Core Collection y Google Scholar. Las razones por las que se utilizaron estas cinco fuentes diferentes para la selección de artículos fueron para que la revisión fuera lo más completa posible, basándose en conjuntos de datos comúnmente utilizados en el campo de las comunicaciones.

Para que un artículo fuese elegible, se debían cumplir cuatro criterios específicos: 1) publicado entre 2009 y 2019; 2) escrito en inglés; 3) publicado en revistas académicas revisadas por pares; y 4), dado que la literatura y la investigación sobre la RSP son extensas, las revistas deben estar indexadas en JCR o Scopus Journals. A pesar de que la investigación de RSP se ha realizado durante muchas décadas, los últimos diez años se seleccionaron como el período específico porque estamos interesados en proporcionar una perspectiva actualizada sobre cómo ha evolucionado la erudición de RSP, incluidas las tendencias de investigación dentro de los recientes discursos, temas y problemas académicos. Para identificar artículos relevantes, se implementaron diferentes búsquedas de palabras clave: "RSP", "medios públicos", "televisión", "televisión pública" y "radiodifusión de servicio público". Por definición, las palabras clave deben formar parte del título, resumen o texto del artículo. 


\subsection{Selección de títulos y resúmenes}

La búsqueda inicial arrojó 232 artículos, que posteriormente se examinaron para detectar duplicaciones y relevancia a través del título y los resúmenes. Los resultados de la búsqueda de literatura se cargaron en Zotero para eliminar los duplicados. Tras la eliminación de artículos repetidos, se recopilaron 122 artículos. Los títulos y resúmenes se leyeron y clasificaron como relevantes o irrelevantes para la revisión de la literatura. Se descartaron los falsos positivos $(n=44)$ ya que algunas palabras clave empleadas en la búsqueda se mencionaron en el título o en el resumen del artículo, pero la investigación no se centró en la RSP. Finalmente, se encontró que setenta y ocho artículos cumplían este criterio.
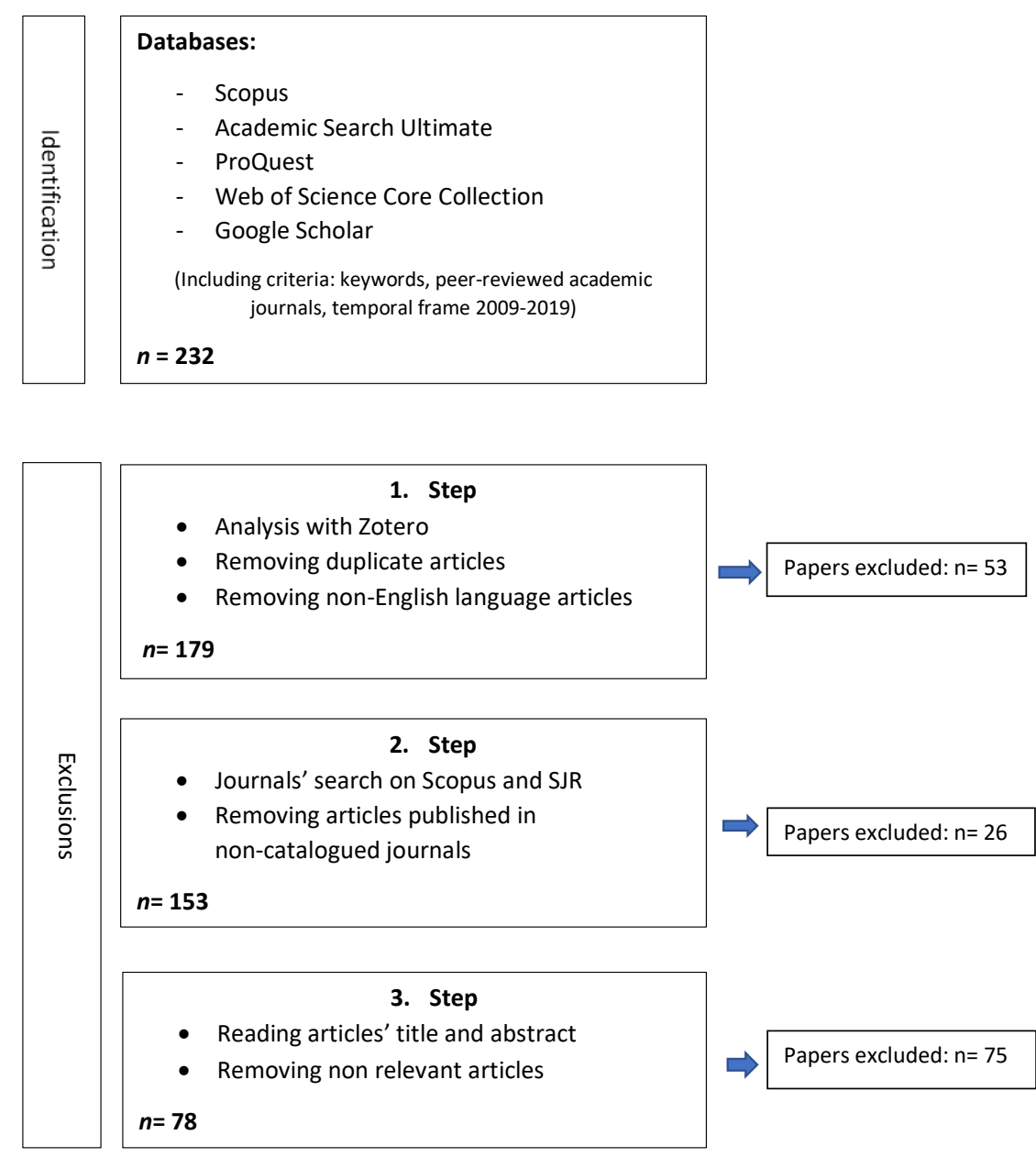

Papers included in analysis: $n=78$

Figura 1: Procedimiento de búsqueda

\subsection{Síntesis y análisis}

Se utilizó un formulario estandarizado y previamente probado para extraer datos de los estudios incluidos para la evaluación de la calidad de los estudios y la síntesis de pruebas. La información extraída se agrupó entre las siguientes variables: revista, fecha, afiliación del primer autor, lugar de recolección de datos, escenario bajo análisis, tipo de artículo, enfoque analítico y métodos. Por tanto, 
se siguió una síntesis de investigación cualitativa agrupando los datos según las variables previamente identificadas. La síntesis de la investigación cualitativa ha demostrado proporcionar medios efectivos para producir una base de conocimiento procesable para informar políticas y prácticas futuras (Denyer y Tranfield 2006). Después de la extracción y síntesis de los datos, los hallazgos se registraron en la Tabla 1 y se resumieron como respuestas narrativas a las preguntas de investigación.

\section{Resultados}

PI1. ¿Cuáles son las principales características de los estudios que analizan la radiodifusión de servicio público?

En total, los estudios sobre la RSP se publicaron en dieciocho revistas diferentes, siendo las más frecuentes Media, Culture \& Society $(\mathrm{n}=11)$, European Journal of Communication $(\mathrm{n}=7)$ e International Journal of Digital Television $(\mathrm{n}=7)$. Si bien se consideraron artículos basados en cualquier país, se ubicaron muchos estudios sobre Europa - especialmente el Reino Unido-lo que, como veremos, implica un predominio de países occidentales y aborda la importancia de profundizar en geografías no occidentales. En cuanto a la fecha de publicación, la gran mayoría de estudios se realizaron entre $2014(n=10)$ y $2015(n=9)$ y $2010(n=8)$ a $2012(n=9)$.

En relación con el país de afiliación del primer autor, catorce autores estaban ubicados en el Reino Unido, seguidos de Bélgica $(n=10)$, Noruega $(n=9)$ y España $(n=8)$. Los antecedentes geográficos de los académicos se ubican principalmente en los países occidentales, especialmente en Europa y América del Norte, incluidos Canadá $(n=1)$ y los Estados Unidos $(n=3)$. Solo unos pocos autores son originarios de Asia $(n=4)$ y uno es de África. El lugar de la recolección de datos refleja una visión más pluralista, con comparaciones entre países como la primera fuente de datos $(n=29)$. De estos 29 estudios realizados en más de un país, los países más frecuentes fueron Reino Unido $(\mathrm{n}=20)$, Bélgica $(n=7)$, Noruega $(n=6)$ y España $(n=6)$. En cuanto a los estudios de un solo país, la principal fuente es Reino Unido $(n=12)$, seguido de Noruega $(n=5)$ y España $(n=4)$. Aunque los artículos analizados se encuentran en cuarenta y ocho países diferentes, la mayoría eran geografías industrializadas como países europeos, Estados Unidos, Canadá, Australia o Nueva Zelanda, con estudios basados en Asia, África y América Central o del Sur en un porcentaje rudimentario (menos del diez por ciento). Esto implica que el estudio de la investigación de la RSP sigue estando poco desarrollado en la mayoría de las geografías no occidentales.

En cuanto al escenario analizado, hemos distinguido quince escenarios diferentes, siendo las Políticas de Medios $(n=17)$ las más prevalentes, seguidas del Marco Regulatorio $(n=14)$ y el modelo RSP $(\mathrm{n}=10)$. Las políticas de medios difieren del marco regulatorio en que las primeras solo se refieren a los procedimientos legales y económicos impuestos por los gobiernos u organismos institucionales. Sin embargo, el marco regulatorio implica la implementación directa de dichos lineamientos, así como diferentes desafíos de los medios y la regulación de audiencia y contenido. Es evidente que la mayoría de los estudios analizados se refieren a la naturaleza política o financiera de los medios públicos. El segundo escenario principal de investigación fue el tipo de plataforma para la investigación de RSP, siendo los Medios Digitales ( $\mathrm{n}=10)$ los más prevalentes, seguidos por el Horario de Televisión $(\mathrm{n}=7)$.

Tabla 1: Características de los artículos seleccionados

\begin{tabular}{ll}
\hline Artículos & Frecuencia \\
\hline \multirow{3}{*}{ Revistas } & Media, culture \& society $(\mathrm{n}=11)$, European Journal of Communication $(\mathrm{n}=7)$, \\
& International Journal of Digital Television $(\mathrm{n}=7)$, The International \\
& Communication Gazette $(\mathrm{n}=6)$, International Journal of Media \& Cultural \\
& Politics $(\mathrm{n}=5)$, Journalism Studies $(\mathrm{n}=5)$, Television \& New Media $(\mathrm{n}=5)$, \\
\hline
\end{tabular}


Nordicom Review $(\mathrm{n}=4)$, Javnost - The Public $(\mathrm{n}=4)$, Journalism $(\mathrm{n}=2)$, Journal of Broadcasting \& Electronic Media $(n=2)$, Journalism \& Mass Communication Quarterly $(n=2)$, Journalism Practice $(n=2)$, Media International Australia $(\mathrm{n}=2)$, Communication, Culture \& Critique $(\mathrm{n}=1)$, Convergence ( $n=1)$, Critical Studies in Media Communication $(n=1)$, Critical Studies in Television $(\mathrm{n}=1)$, Digital Journalism $(\mathrm{n}=1)$, El profesional de la Información ( $n=1)$, Global, Media \& Communication $(n=1)$, Info $(n=1)$, International Journal of Cultural Studies $(\mathrm{n}=1)$, Journalism \& Communication Monographs ( $\mathrm{n}=1)$, Middle East Journal of Communication $(\mathrm{n}=1)$, Mobile, Media \& Communication $(\mathrm{n}=1)$, Observatorio $\left(\mathrm{OBS}^{*}\right)(\mathrm{n}=1)$, Trames $(\mathrm{n}=1)$. $2014(\mathrm{n}=10), 2015(\mathrm{n}=9), 2011(\mathrm{n}=9), 2012(\mathrm{n}=9), 2010(\mathrm{n}=8), 2016(\mathrm{n}=8)$, Fecha $2009(\mathrm{n}=6), 2013(\mathrm{n}=6), 2018(\mathrm{n}=5), 2017(\mathrm{n}=4), 2019(\mathrm{n}=4)$.

Reino Unido $(n=14)$, Bélgica $(n=10)$, Noruega $(n=9)$, España $(n=8)$, Origen del primer Alemania $(n=5)$, Finlandia $(n=4)$, Países Bajos $(n=3)$, EE. UU. (N=3), Italia autor $(n=2)$, Australia $(n=2)$, Estonia $(n=2)$, Grecia $(n=2)$, Israel $(n=2)$, Serbia $(n=$ 2), Suecia $(n=2)$, Austria $(n=1)$, Bahamas $(n=1)$, Canadá $(n=1)$, China $(n=1)$, Dinamarca $(\mathrm{n}=1)$, Macedonia $(\mathrm{n}=1)$, Jordania $(\mathrm{n}=1)$, Tanzania $(\mathrm{n}=1)$.

Comparación cruzada $(n=29)$, Reino Unido $(n=12)$, Noruega $(n=5)$, Unión

\begin{tabular}{|c|c|c|}
\hline $\begin{array}{l}\text { Lugar } \\
\text { recopilación } \\
\text { datos }\end{array}$ & $\begin{array}{l}\text { de } \\
\text { de }\end{array}$ & $\begin{array}{l}\text { Europea }(n=4) \text {, España }(n=4) \text {, Bélgica }(n=3) \text {, Estados Unidos }(n=3) \text {, países } \\
\text { arabes }(n=2) \text {, Alemania }(n=2) \text {, Finlandia }(n=2) \text {, Serbia }(n=2) \text {, Australia }(n=\text {, } \\
1) \text {, Canadá }(n=1) \text {, China }(n=1) \text {, Estonia }(n=1) \text {, Grecia }(n=1) \text {, Italia }(n=1) \text {, } \\
\text { Suecia }(n=1) \text {, Suiza }(n=1) \text {, Tanzania }(n=1) \text {, Países Bajos }(n=1) \text {. } \\
\text { Políticas de medios }(n=17 \text { Marco regulatorio }(n=14) \text { Modelo RSP }(n=10)\end{array}$ \\
\hline & & $\begin{array}{l}\text { Políticas de medios }(n=17) \text {, Marco regulatorio }(n=14) \text {, Modelo RSP }(n=10) \text {, } \\
\text { Medios digitales }(n=10) \text {, Horario de televisión }(n=7) \text {, Participación de la }\end{array}$ \\
\hline $\begin{array}{l}\text { Escenario } \\
\text { análisis }\end{array}$ & bajo & $\begin{array}{l}\text { Medios digitales }(n=10) \text {, Horario de televisión }(n=7) \text {, Participación de } \\
\text { audiencia }(n=4) \text {, Sitios de redes sociales }(n=4) \text {, modelo de negocio }(n=3 \\
\text { partes interesadas }(n=3) \text {, convergencia de medios }(n=2) \text {, contenido de notici } \\
(n=2) \text {, trabajo periodístico }(n=1) \text {, asistencia de medios }(n=1) \text {. }\end{array}$ \\
\hline Tipo de artículo & & Empírico $(\mathrm{n}=61)$, Conceptual $(\mathrm{n}=17)$. \\
\hline
\end{tabular}

Enfoque analítico Cualitativo $(n=40)$, Conceptual $(n=17)$, Cuantitativo $(n=15)$, Mixto $(n=6)$.

En cuanto al tipo de artículo, la gran mayoría de los trabajos fueron empíricos (n=61) y, por tanto, basados en evidencias. Diecisiete estudios fueron conceptuales, basados en descripciones teóricas del modelo de los medios públicos o los desafíos financieros o estructurales de los sistemas de televisión de diferentes países, especialmente los subdesarrollados. Los métodos cualitativos fueron el enfoque analítico principal $(\mathrm{n}=40)$, mientras que quince estudios implementaron métodos cuantitativos y seis aplicaron métodos mixtos (combinación de enfoques cualitativos y cuantitativos). Significativo para los métodos empleados, el principal procedimiento metodológico fue la combinación de diferentes técnicas $(n=20)$. En cuanto a los estudios de método único, el Estudio de Caso Comparativo $(n=9)$ fue la técnica más frecuente, seguida del Análisis de Contenido $(n=8)$, el Estudio de Caso Único (n=8) y las Entrevistas a Expertos $(n=7)$. Finalmente, el instrumento de encuesta $(n=7)$ se implementó en combinación con otras técnicas, como Entrevistas a Expertos $(n=2)$ o Análisis de Contenido $(n=2)$.

PI2. ¿Cuáles son los principales temas y patrones temáticos de los estudios que analizan la Radiodifusión de Servicio Público?

En cuanto a los principales patrones temáticos, se identificaron cuatro líneas de investigación diferentes: 1) digitalización y desarrollo de nuevas tecnologías, 2) modelo de negocio y financiamiento, 3) políticas y regulación, y 4) valor público e interés ciudadano. Las preguntas de investigación que se describen a continuación no son representativas de todos los artículos incluidos, pero ilustran el principal interés de investigación de cada corriente de investigación.

Digitalización y desarrollo de nuevas tecnologías: las preguntas sobre esta línea de investigación incluyen las siguientes: a) ¿Qué desafíos y amenazas enfrentan las RSP debido al nuevo panorama de 
los medios y el desarrollo tecnológico ?; b) ¿Hasta qué punto el nuevo sistema de medios y los servicio de redes sociales tienen un impacto sobre las RSP?; c) ¿Cuáles son las implicaciones y consecuencias para las RSP en plataformas digitales?; y d) ¿Cómo las cadenas públicas logran agregar valor en los medios multiplataforma sin perder intereses comerciales?

Modelo de negocio y financiación: las preguntas sobre esta línea de investigación son las siguientes: a) ¿Cuáles son los principales modelos financieros de las RSP en un panorama de mercado libre? b) ¿Cuáles son las consecuencias y requisitos de adoptar un enfoque comercial ?; c) ¿Cuáles son los impactos de la globalización y la privatización?; y d) ¿Cómo compiten las RSP con las emisoras privadas?

Políticas y regulación: Las preguntas sobre esta línea de investigación incluyen las siguientes: a) ¿Cuál es el papel del gobierno en el ámbito de la RSP?; b) ¿Cuáles son las obligaciones y restricciones sociales y democráticas de la RSP?; c) ¿Quién es responsable de las regulaciones de RSP?; d) ¿Hasta qué punto es legítima la influencia política?; e) ¿Cuáles son las consecuencias de adoptar un modelo de desregulación?; f) ¿Cómo pueden sobrevivir las RSP sin ninguna intervención gubernamental en un mercado competitivo?; y g) ¿Cómo mantiene una RSP sus principios tradicionales y democráticos mientras compite con las emisoras privadas?

Valor público e interés ciudadano: Las preguntas sobre esta línea de investigación son las siguientes: a) ¿Cuál es el papel y la definición de los objetivos, la misión y los valores de la RSP?; b) ¿Cuáles son los pilares de la RSP?; c) ¿Qué importancia tienen los espectadores y los ciudadanos para la RSP?; d) ¿Cuáles son las características del contenido de las RSP?; y e) ¿Cómo asegura una RSP la democracia?

Para cada grupo temático, hemos identificado los siguientes temas:

\subsection{Digitalización y Nuevas tecnologías}

Transición y conversión digital: cinco artículos analizan la transición de la radiodifusión analógica a la retransmisión digital o TDT (Candel 2011; Evens, Verdegem y De Marez 2010; Iosifidis 2011; Michalis 2016; Taylor 2016). Desde principios de la década de 2000, las nuevas tecnologías y los desarrollos digitales han desafiado a la RSP, que tuvo que adaptarse constantemente a nuevos formatos, servicios y rutinas de producción. La transición a la TDT es un claro ejemplo de los desafíos de la RSP debido a las diversas decisiones políticas y financieras que implica su despliegue. El cambio requirió una enorme inversión económica y una rápida innovación tecnológica, para lo que muchos países no estaban preparados y, por lo tanto, no pudieron manejarlo adecuadamente. Sin embargo, el principal problema que tuvieron que enfrentar las RSP fue la llegada de múltiples emisoras privadas, lo que ha llevado a un aumento de la competencia y a un dominio de la lógica del libre mercado sobre el panorama de los medios - en conflicto con los objetivos y obligaciones de la RSP tradicional (Candel 2011). Más específicamente, las RSP deben encontrar formas innovadoras y sostenibles de introducir el valor público en un entorno más competitivo en el que las emisoras comerciales puedan llegar a un público más amplio a través de programas populares y el género de entretenimiento. "El debate a menudo seco y técnico sobre la gestión del espectro radioeléctrico no puede ocultar lo que realmente está en juego: cómo adaptar y asegurar los valores de RSP en el entorno de los medios emergentes, independientemente de qué plataforma(s) de transmisión tengan éxito" (Michalis 2016, 348). Estudios anteriores han demostrado que - considerando la nueva lógica orientada al mercado-la RSP necesita más regulación y supervisión para evitar actividades comerciales y publicitarias y garantizar sus principios tradicionales y los beneficios de las partes interesadas (Evens, Verdegem y De Marez 2010) 
Uso de las redes sociales: como se explicó anteriormente, la digitalización ha desafiado a las RSP de varias formas importantes. En esta categoría, los artículos incluidos han observado los desafíos que enfrentan las emisoras públicas que intentan mantener una presencia precisa y equilibrada en las redes sociales: "con el potencial de la multimedia en red, la Web ha desafiado al periodismo a adaptarse a sus capacidades, por ejemplo, incorporando audio y video y agregando encuestas, cuestionarios, comentarios o juegos a los reportajes de noticias basados en texto" (Sjøvaag, Stavelin y Moe 2015, 11). Ciertos estudios (Horsti y Hultén 2011; Evans 2018) han analizado el impacto de la competencia creada por las redes sociales, lo que ha llevado al desarrollo de nuevas estrategias y prácticas para llegar y atraer más espectadores y obtener ingresos suficientes para mantener la estabilidad financiera. Según algunos estudios (Moe 2013; Stollfuß 2018; van Dijck y Poell 2015), el principal desafío de las redes sociales de RSP es el conflicto entre su carácter público y los intereses comerciales y privados que dominan las plataformas digitales. Según Stollfuß (2018), los procesos de configuración y algoritmos de las redes sociales han transformado las condiciones de información y formas de comunicación de una ciudadanía democrática.

Estos sitios se caracterizan por su acceso universal y distribución pública gratuita; sin embargo, para garantizar su estabilidad, los servicios de redes sociales - u otras plataformas, incluidas Google o YouTube-permiten que las empresas de terceros anuncien sus productos y servicios, lo que va en contra de los principios tradicionales y la financiación pública de las RSP:

Apple y Google se han ofrecido a compartir los ingresos con los proveedores de contenido,

pero los términos ofrecidos aún no han resultado atractivos. Pueden surgir nuevos modelos

comerciales [...] Pero dicha estrategia comercial depende de que los espectadores sean

accesibles $[\ldots]$ y puede que no contribuyan mucho a financiar el contenido público. [...] En

consecuencia, los ingresos publicitarios generados a partir de videos a pedido y/o canales de

deportes o películas pueden no fluir para financiar noticias e información pública. (Collins,

2011, 1210).

Participación y compromiso de la audiencia: este tema se refiere a la transformación constante de los hábitos de consumo y visualización de la audiencia. El panorama de los nuevos medios ha convertido el papel de la audiencia en uno más activo y participativo: "las producciones multiplataforma solo brindan a la televisión nuevas formas de interactividad ya que el medio de uno a muchos va acompañado de otros medios de muchos a muchos" (Keinonen y Klein Shagrir 2017, 72). Una estrategia de RSP (y de las emisoras privadas) para llegar e involucrar a más espectadores es desarrollar contenidos más participativos e interactivos en los que los espectadores actúen como participantes (Enli e Ihlebæk 2011). El objetivo de esta táctica es dar voz a los espectadores e incluirlos en la producción del contenido, logrando la lealtad y la universalidad: "este nuevo panorama socio-técnico está empoderando al especta-usuario con una voz-movilizada en gran parte a través de las redes sociales - y con opciones - proporcionando una pluralidad de contenidos y herramientas que permiten a los especta-usuarios mapear sus propias trayectorias autodirigidas a través de este entorno multiplataforma" (Kant 2014, 383). Sin embargo, algunos estudios han demostrado que esta estrategia en realidad responde a intereses privados y económicos, ya que la participación e interacción de la audiencia no conduce directamente a una producción más democrática y horizontal, sino a un incremento de la competencia, un aumento de los ingresos por financiamiento y la fragmentación de 
la audiencia. Solo uno de los estudios antes mencionados (Millanga 2014) ha demostrado que el uso de nuevas tecnologías, como el teléfono móvil, se ha traducido en una comunicación más horizontal y recíproca, porque los ciudadanos de diferentes sectores y condiciones de la población son capaces de discutir abiertamente asuntos públicos y locales. Sin embargo, es importante señalar que este estudio se realizó en países subdesarrollados de África, donde el servicio de radiodifusión tradicional se caracteriza por un control estatal completo. Por lo tanto, la incorporación de tecnologías interactivas ha dado voz a las diferentes minorías y etnias, lo que no significa que las emisoras y los productores, en realidad, escuchen estas nuevas voces.

Convergencia: Cinco de los artículos abordan los procesos y modelos de convergencia impuestos por el desarrollo digital y los formatos multiplataforma:

El campo de la comunicación lleva años defendiendo un modelo de transmisión capaz de

aglutinar lo mejor de los viejos y nuevos medios, con el resultado de que, en la etapa actual, la relación de los medios online con los tradicionales ha dejado de entenderse en términos de sustitución y subordinación, y ha dado paso a nuevas concepciones basadas en la complementariedad y la coordinación. (Larrondo et al. 2012, 790).

Dos estudios incluidos en esta sección se centran en el impacto de la convergencia sobre el trabajo y las prácticas de los periodistas (Larrondo et al. 2016; Värk y Kindsiko 2019). La confluencia de diferentes medios, como la fusión de la radio, la televisión y las sedes de periódicos en una sola empresa, implica nuevas rutinas y hábitos profesionales caracterizados por la colaboración, la cooperación y las actitudes polivalentes, lo que sugiere menores grados de especialización y mayores niveles de competencia y carga de trabajo (Larrondo et al. 2016). Los otros tres artículos (Larrondo et al.2012; Puijk 2015; Vanhaegh y Donders 2016) se centran en los desafíos de los países europeos para transformar la RSP en MSP, o Medios de Servicio Público, que son, en esencia, la necesidad de una mayor interacción y co-creación y la adaptación de sus rutinas y formatos tradicionales a los nuevos medios para llegar a los espectadores. Sin embargo, este cambio implica más competencia: "las audiencias de los medios tradicionales, especialmente la prensa, están disminuyendo, los hábitos de consumo de noticias han cambiado y los ingresos publicitarios están disminuyendo, mientras que hay una competencia creciente para retenerlos" (Larrondo et al. 2016, 278), ya que las emisoras públicas y privadas tienen acceso a los mismos servicios y tecnologías.

\subsection{Modelo de negocio y financiación}

Competencia y conflicto con las emisoras comerciales: la digitalización y la evolución tecnológica han planteado varios desafíos a las RSP, no solo en cuanto a formatos y servicios, sino también a la financiación y los ingresos financieros. El entorno de los medios contemporáneos está definido por la privatización de los medios:

A medida que se accede a más y más contenido de los medios a través de Internet de banda

ancha, las emisoras públicas como ABC y SBS enfrentan el problema de que-en contraste con sus servicios de transmisión — cada aumento incremental en la demanda de contenido en 
línea trae costos de entrega adicionales, por lo que pueden enfrentar la "maldición de la creciente popularidad", ya que aumenta los costos sin aumentar los ingresos. (Flew 2009, 10).

Como ejemplifican algunos artículos (Curran et al. 2009; D’Arma 2018), la privatización de los medios de comunicación estimula la economía e implica un mayor esfuerzo para llegar a las audiencias, lo que las emisoras justifican como un beneficio para el público; si hay más competencia para asegurar la participación de la audiencia, se ofrecerán contenidos más innovadores y de calidad para atraer espectadores. Sin embargo, los resultados han demostrado que el resultado es en realidad el contrario y, si hay más competencia, el contenido y el proceso de producción de la radiodifusión pública serán menos democráticos. Esto ocurre debido al contenido suave y superficial proporcionado por las emisoras comerciales. Al tratar de llegar e involucrar a más consumidores, los canales privados ofrecen contenido popular y trivial (como entretenimiento o programas populares), ya que este tipo de programación se adapta a todas las audiencias, lo que lleva a la remodelación del contenido de RSP para acercarse a las emisoras privadas y, por lo tanto, a la falta de calidad e información de los programas públicos. Entonces, el problema es asegurar el valor público y el interés ciudadano mientras se compite con actores privados. Para lograrlo, los estados e instituciones han optado por la financiación pública y la regulación de los medios de comunicación para garantizar una ciudadanía democrática y bien informada. Así, las emisoras públicas reciben subsidios gubernamentales que se utilizan para garantizar programas que no generan suficientes ingresos para mantener su producción, como lo hacen los programas culturales o de asuntos públicos (Curran et al. 2009). Siguiendo esta estrategia, se requiere que RSP diferencie su financiamiento y actividades públicas de las comerciales, como publicidad o alianzas, para asegurar que el financiamiento público se dedique al interés público, lo que significa que los ingresos gubernamentales e institucionales no están subsidiando intereses privados (Flynn 2015).

La financiación pública ha resultado insuficiente para garantizar un servicio público de alta calidad en el actual sistema de medios. Por ello, la mayoría de las emisoras públicas han optado por un modelo o formatos publicitarios mixtos. Sin embargo, como señala Jakubowicz (2007), es necesario garantizar los principios de la RSP — como el interés de los ciudadanos, la diversidad de contenidos, el pluralismo, la inclusión social y los valores democráticos - al tiempo que se adquiere financiamiento de otras fuentes: "el dinero es un factor relevante cuando uno apunta a hacer programas sobresalientes (y producidos en el país)" (Donders 2010 69). Sin embargo, las empresas privadas han denunciado esta estrategia como una competencia desleal, ya que las emisoras comerciales son financiadas íntegramente por operaciones privadas y de mercado y están compitiendo en el mismo entorno que las emisoras públicas, que también se benefician de los presupuestos públicos:

El acceso exclusivo (es decir, no competitivo) de las RSP a la financiación pública se caracterizó por otorgar un "estatus privilegiado" (Ward 2004: 93) a esas emisoras. Esta condición fue impugnada en una serie de acciones legales a nivel europeo en la década de 1990: los actores comerciales de Francia, Italia, España, Portugal e Irlanda presentaron demandas judiciales en el sentido de que la financiación pública de las emisoras públicas, a través de derechos de licencia o subvención directa, constituía una ayuda estatal incompatible con las disposiciones del Tratado de Roma sobre derecho de competencia. (Flynn 2015, 127). 
Así, en el caso de la Unión Europea, la solución ha sido limitar el mandato de servicio público para asegurar una competencia leal entre actores públicos y privados y evitar que la RSP se dedique a actividades destinadas a obtener beneficios económicos.

Modelos mixtos: como se ilustró anteriormente, algunas emisoras se benefician de sistemas de financiación tanto públicos como privados. Al tiempo que brindan contenido informativo diverso y de alta calidad, las emisoras públicas realizan actividades comerciales y permiten contenido publicitario en su programación para evitar la intervención política y la dependencia institucional. Esto se debe a que el entorno competitivo creado por las contrapartes comerciales está destinado a conducir a una mayor diversidad de contenido (Smith 2009). El ejemplo más popular de este sistema dual es la Corporación Británica, BBC, que fue la primera en combinar fondos públicos y privados para asegurar la imparcialidad y los recursos suficientes para crear contenido de calidad y preservar el interés de los ciudadanos (Ramsey 2016). Como han explicado algunos estudios (Donders y Raats 2015; Mjøs 2011; Smith 2009), los modelos mixtos permiten a las RSP servir al público y ofrecer contenido local, cultural y plural que corresponda a algunos de sus principales valores. Así, gracias a las actividades publicitarias y las estrategias orientadas al mercado, las emisoras públicas pueden afrontar los costes de los procesos productivos y la inversión tecnológica. Sin embargo, en la mayoría de los casos, las emisoras están bajo presión política para legitimar su carácter público y modelo financiero, así como para demostrar que la financiación pública satisface las necesidades y requisitos del público (Johnson 2013).

\subsection{Políticas y regulación}

Enfoque de múltiples partes interesadas: en algunos países europeos-como el Reino Unido, Alemania y Suecia-las emisoras públicas recurren a la consulta de múltiples partes interesadas para asegurar la diversidad, la pluralidad y los valores democráticos en la programación de la RSP. El objetivo de esta estrategia es incluir más actores involucrados en los procesos de regulación y producción para garantizar el interés público y la inclusión de contenido educativo y cultural (Donders y Raats 2012; Van den Bulck y Donders 2014). Sin embargo, la investigación actual ha demostrado que el enfoque de múltiples partes interesadas - al tiempo que trata de garantizar la democracia, el consenso y una mayor representación e inclusión de todos los grupos de la sociedad - ha demostrado ser lo opuesto a la democracia. Existe un dominio de algunos agentes, especialmente los comerciales, lo que se traduce en una priorización del interés privado sobre el valor público (Donders, Van del Bulck y Raats 2019).

Regulación e influencia del gobierno: una estrategia para garantizar la democracia y preservar el interés público es la regulación del gobierno (Ginosar y Krispil 2015). Una RSP, en sus orígenes, debe servir al público y satisfacer las demandas y necesidades sociales y locales. Por tanto, algunos gobiernos deben supervisar y controlar las prácticas de radiodifusión, como la RSP española, en el que la normativa institucional moldea el campo de la comunicación y los procesos audiovisuales (Fernández Alonso et al. 2010). Además, como explica Ogus (2004), la supervisión gubernamental sirve para garantizar el valor público reflejando todas las actitudes políticas y corrigiendo las fallas del mercado: "identificando las fallas del mercado que justifican la intervención estatal y seleccionando los métodos de intervención que de manera predecible corregirán esa falla al menor costo" (Ginosar y Krispil 2015, 4). Sin embargo, algunos estudios han demostrado que la influencia política e ideológica sobre la RSP no beneficia a la democracia ni a la ciudadanía, sino que, más bien, se traduce en una falta de independencia y autonomía de los medios de comunicación que beneficia los intereses privados y las preferencias políticas (Arriaza Ibarra 2013). Además, en otros casos-incluidas las geografías no desarrolladas o los países exsocialistas, como China - el control de las ayudas estatales da como 
resultado la manipulación ideológica y la reducción de los derechos: "la falta de énfasis en la igualdad individual y la subordinación de la libertad individual a los intereses colectivos y estatales en la Constitución china, así como por la práctica del gobierno de implementar los derechos colectivos a la subsistencia y el desarrollo antes que los derechos civiles y políticos" (Chan Chin 2012, 907).

Enfoque neoliberal y proceso de desregulación: Tres estudios analizan los procesos de desregulación y las prácticas neoliberales de la RSP para evitar la intervención política. Como indica Dawes (2014, 707), la supervisión del gobierno influye en la producción y distribución de los medios a favor de las preferencias ideológicas:

... la construcción del público como una ciudadanía pasiva de beneficiarios de ayudas estatales,

que requiere la interferencia del estado y por lo tanto compromete su libertad del estado (y la

legitimidad del estado liberal como uno que no interfiere en el ámbito privado), rompió la

distinción público-privada entre política y economía, y socavó tanto como los procesos de

mercado, la capacidad de los ciudadanos para formar un público activo y hacer que el poder

político rinda cuentas.

Por lo tanto, algunas emisoras han optado por un modelo desregulado caracterizado por la independencia de los medios, la imparcialidad y un sistema impulsado por el libre mercado, porquecomo señala Larsen (2014) —el mercado está mejor calificado que los gobiernos para preservar la independencia de los ciudadanos. Sin embargo, Thussu (2007) argumenta que la autonomía de los medios - aunque implica más competencia - amenaza la democracia porque los espectadores son considerados consumidores, no ciudadanos, y los procesos de producción están sometidos al lucro económico, lo que lleva a contenidos de mala calidad y priorización de géneros populares: "La televisión pública se vende cada vez más y la competencia del mercado está remodelando los valores del género informativo televisivo. El entorno de la información, en otras palabras, está disminuyendo a medida que se privatizan los mercados de medios" (Cushion, Lewis y Ramsay 2012, 832).

Países pequeños, terceras democracias y naciones subdesarrolladas: la RSP es un elemento central de las democracias europeas, así como de otros países, incluidos Australia, Canadá y Estados Unidos. Sin embargo, en países pequeños o geografías subdesarrolladas, el papel de la RSP ha demostrado ser diferente. En dos artículos se ha observado el papel de la RSP en países pequeños como Macedonia, Finlandia y Serbia, donde hay poco espacio para las emisoras y los comercializadores privados, ya que el tamaño de su población es insuficiente para económicamente motivador. Por lo tanto, los gobiernos de estos países tienen más responsabilidad de ofrecer y garantizar diversidad, información y alta calidad en el contenido de la RSP. En este caso, la estrategia seguida por las emisoras públicas y los reguladores fue la opuesta a la de otros países europeos. El objetivo era garantizar la presencia de empresas privadas en el panorama de los medios y asegurar la competencia comercial porque la falla del mercado era inasequible para los presupuestos de la RSP (Jõesaar 2011).

Sin embargo, en geografías no democráticas y terceras democracias, Aaron Rhodes (2007) vio la implementación de la RSP como un camino hacia la democracia y una estrategia para lograr la transformación social y política: "los medios estables, independientes y funcionales son vistos como un medio para lograr objetivos democráticos más amplios. Los objetivos específicos de los medios se centran en el establecimiento y el apoyo de instituciones de medios independientes. El apoyo a la 
reforma de la RSP podría incluirse en objetivos tanto políticos como específicos de los medios" (Marko 2015, 294). Lo mismo puede decirse de los países árabes donde la RSP fue una herramienta esencial para desarrollar la democracia y la participación de los ciudadanos en los asuntos públicos (Ayish 2010). La Unión Europea y otras instituciones amplias han guiado el modelo de radiodifusión pública de estas naciones para desarrollar la independencia y la democracia de los medios de comunicación. Sin embargo, algunos estudios (Ayish 2010; Marko 2015) han demostrado que la transformación de los medios no resultó en cambios políticos porque los contextos sociales y culturales de cada nación siguen siendo dominantes.

Unión Europea y homogeneización: La Unión Europea es fundamental en la regulación y financiación de los medios para todos los estados miembros. Algunos estudios (Just, Latzer y Saurwein 2012; Spasovska e Imre 2015; Van den Bulck y Moe 2012) analizan las presiones de la UE para distinguir entre financiación pública y comercial y justificar el mandato público como herramienta para proteger la democracia y garantizar la transparencia y la independencia. Algunos estudios (Donders y Pauwels 2010; Psychogiopoulou 2013) han demostrado que las directrices de la UE tienen un carácter global y homogéneo que no considera las particularidades y el contexto de cada nación, lo que genera varios desafíos ya que las características nacionales predominan sobre los mandamientos comunes (Van den Bulck y Moe 2012). En este caso, ha fallado la implementación de nuevos formatos o servicios, como la ya mencionada transición a la TDT. Tres artículos han observado una transformación reciente en las prácticas de la UE de una actitud reguladora a una prevalencia del libre mercado. Esta resolución ha llevado a la implementación de una prueba que los estados miembros deben aplicar para aprobar nuevos servicios (Donders y Pauwels 2010; Van den Bulck y Moe 2012; Just et al. 2012). Las pruebas constan de dos pasos - evaluación del valor público e impacto en el mercado: "por un lado, se debe evaluar el valor público de los nuevos servicios de medios. Por otro lado, también deben calcularse sus efectos positivos y negativos en el mercado (Comisión Europea 2009). Sobre la base de estos dos componentes, los gobiernos deben aprobar la prestación de un servicio" (Donders y Pauwels 2010, 137). Siguiendo esta estrategia, los gobiernos aclaran el papel de la RSP y garantizan los principios tradicionales evitando la participación de la RSP en actividades comerciales.

\subsection{Valor público e interés ciudadano}

Rol público e interés ciudadano: desde sus orígenes, las RSP, especialmente en Europa, han mantenido un papel democrático y sirven a los ciudadanos: "en general, [la] RSP puede considerarse como 'un pilar importante del proceso democrático'” (Iyengar 2009; citado en Jacobs, Meeusen y D'Haenens 2016, 3). El rol y el valor público de una RSP nunca se han definido oficialmente. Sin embargo, como explican algunos artículos (Esser y Majbritt Jensen 2015; Sjøvaag, Pedersen y Owren 2019), la RSP debe proporcionar a los ciudadanos contenido de alta calidad, diverso y tolerante, garantizar el acceso universal e informar a cada grupo social. Como declara el Tratado de Ámsterdam sobre RSP (1997), “el sistema de radiodifusión pública en los Estados miembros está directamente relacionado con las necesidades democráticas, sociales y culturales de cada sociedad y con la necesidad de preservar el pluralismo mediático"' (citado en García de Madariaga, Lamuedra Graván y Tucho Fernández 2013, 911). Además, las RSP deben suplir la falla del mercado, garantizar que los ciudadanos estén bien informados y utilizar fondos públicos para garantizar la democracia y la transparencia (Sjøvaag et al. 2019). Sin embargo, las RSP enfrentan varios desafíos debido al impacto del mercado y la digitalización, como se mencionó anteriormente. Por lo tanto, las RSP deben encontrar un equilibrio entre el contenido popular y suave, que atrae a grandes sectores de la población (como entretenimiento o sensacionalismo), y programas informativos y culturales, que ayudan a mantener la calidad y el estatus de la RSP (Esser y Majbritt Jensen 2015). 
Educar e informar: La educación y la cultura son algunos de los principales valores de las RSP. Sin embargo, este tipo de programación no atrae a las emisoras privadas y comerciales por su participación de audiencia y escasos ingresos que no cubren los costos de producción y distribución (Huntsberger 2014; Pajala 2010; Shepperd 2014; Steemers y D’Arma 2012). Por lo tanto, los programas educativos y culturales se consideran una falla del mercado que las RSP deben suministrar y proporcionar, de la siguiente manera: "todavía es probable que haya brechas importantes en la oferta del mercado y, por lo tanto, sigue existiendo una justificación continua para una fuerte presencia de RSP en esta área" (D'Arma y Labio 2017, 2). Sin embargo, como hemos visto, las RSP deben encontrar un equilibrio entre el éxito comercial y la popularidad y los valores públicos y culturales. Para ello, algunas emisoras públicas han priorizado lo que Grummell (2009) denomina edinfotainment - contenido educativo y cultural adaptado al género del entretenimiento y a los formatos y programas populares: "los productores educativos adoptaron nuevos estilos y estrategias de programas para atraer espectadores, mezclando material educativo con estrategias de entretenimiento e información de la radiodifusión convencional" (Grummell 2009, 276).

Distinción: en un entorno más competitivo y comercial, las RSP deben diferenciarse de sus contrapartes privadas para atraer espectadores y asegurar ingresos: "incentiva a la audiencia a permanecer dentro del contenido de una vertical o crea publicidad a su alrededor, aumentando así el potencial de generar ingresos publicitarios" (Ejbye Sørensen 2013, 43). Para lograr esto, algunas emisoras, incluida la BBC, han optado por un modelo mixto: "aquí el carácter distintivo parece estar asociado con la innovación, la asunción de riesgos, el volumen general de lo que el informe llama 'géneros RSP' en el momento pico (identificado más bien estrechamente como 'que incluye hechos especializados, artes, música clásica y comedia'), 'géneros y programas desafiantes', así como 'innovación de servicios"' (Goddard 2017, 1902). Siguiendo esta estrategia, la BBC pudo crear una marca real como garantía de calidad; así, la emisora británica puede permitirse diferentes estrategias multiplataforma para llegar a un público más amplio en el Reino Unido y en todo el mundo: "proporcionar seguridad de marca a los espectadores, visitantes y productores de documentales. Por lo tanto, para ser un sitio exitoso no es solo la capacidad de producir o entregar contenido documental lo que importa, la capacidad de dar fe de su calidad es igualmente importante" (Ejbye Sørensen 2013, 39).

Diversidad y pluralismo: estos valores son también dos principios fundamentales de las RSP. En este caso, las nuevas tecnologías han supuesto una ventaja para las RSP, mientras que su desarrollo ha proporcionado a las emisoras públicas formas avanzadas y económicas de llegar a todos los grupos de la sociedad: "los nuevos servicios de difusión restringida y bajo demanda están ampliando las formas de ofrecer servicios de medios, aportando más medios, en lugar de desplazar la radiodifusión" (Debrett 2009, 816). Así, se garantiza la expresión e inclusión de minorías y etnias, así como el acceso universal: "desde la perspectiva de la representación social, grandes grupos de ciudadanos, en comparación con las minorías, tienen una mayor capacidad para organizar sus intereses y ser visibles en los medios de comunicación masiva" (Mangani Tarrini 2018, 284). No obstante, la investigación en esta área (Engelbert y Award 2014; Ala-Fossi y Lax 2016) ha demostrado que las nuevas tecnologías y servicios dependen de factores económicos, lo que va en contra de los principios básicos de las RSP y lleva a los estados y gobiernos a regular las actividades en línea de las RSP para verdaderamente garantizar el pluralismo y la diversidad.

\section{Estudios de RSP: limitaciones e investigaciones futuras}

Los crecientes desafíos y dificultades de la RSP y los Medios Públicos para mantener su estatus y posición como un servicio democrático han permitido una nueva agenda de investigación para los científicos sociales. En este contexto, las RSP pueden ser fundamentales para ampliar y preservar el 
interés público y cultural en las sociedades democráticas, así como para garantizar una ciudadanía bien informada. Basado en la revisión de artículos relevantes, este estudio encontró deficiencias claras en la investigación de RSP durante la última década. Esto incluye la falta de posibles estrategias o soluciones para enfrentar los desafíos actuales de la RSP, descuidar los enfoques cualitativos para la calidad y características de los programas de RSP, la investigación limitada sobre estrategias multiplataforma y la gestión de redes sociales además de la BBC y la ausencia de un análisis cultural en un sentido amplio - es decir, música, cine o artes escénicas. En la siguiente sección, el artículo ofrece críticas y sugerencias sobre cómo debería progresar la investigación de la RSP.

\subsection{Proporcionar posibles estrategias para enfrentar los desafíos de la RSP}

Como se refleja en el análisis cualitativo, la situación actual de la RSP es desafiante debido a los diferentes obstáculos que deben enfrentar las emisoras públicas. Aunque algunos estudios han identificado y definido las fases e inconvenientes a la hora de financiar RSP (Collins 2011; D'Arma 2018; García de Madariaga, Lamuedra Graván y Tucho Fernández 2013) o adoptar contenidos y formatos a plataformas digitales (Ejbye Sørensen 2013; Moe 2013; Van Dijck y Poell 2015; Stollfuß 2018), este análisis descansa en un nivel superficial, ya que la mayoría de los estudios describen la difícil situación actual para las emisoras públicas. Sin embargo, cada estudio ofrece propuestas precisas y relevantes para afrontarla. Por lo tanto, aún es necesario investigar las posibles soluciones y estrategias para gestionar adecuadamente los obstáculos de la RSP.

Para abordar y resolver esta situación crítica, las futuras investigaciones de la RSP deben detectar no solo los desafíos que amenazan el estatus de la RSP y sus consecuencias adversas, sino sus orígenes, tratando de identificar las estrategias y actores involucrados. Sobre la base de las experiencias previas de las emisoras públicas, tanto los éxitos como los fracasos-como la implementación de la TDT o la adopción de modelos mixtos-las investigaciones futuras deberían proponer formas alternativas de competir con las emisoras comerciales y los sitios de redes sociales o reconfigurar el modelo de financiación. Por lo tanto, si la investigación existente y actual ha demostrado ampliamente que el plan actual de la RSP ha fracasado, se debe continuar una línea de investigación para volver a analizar e identificar los errores anteriores para reformar las tácticas de la RSP. Además, se necesita un enfoque cualitativo para probar las posibles soluciones en diferentes escenarios, como las distintas plataformas multimedia o servicios de varias emisoras públicas de diferentes países, para asegurar y validar la eficiencia de las posibles soluciones.

\subsection{Calidad y características de los programas públicos}

Aunque la investigación sobre RSP es extensa, la mayoría de los estudios se mantienen en medidas políticas, financieras o regulatorias (D'Arma y Labio 2017; Ramsey 2016) y pocos de ellos se enfocan en la calidad y características de los contenidos (Evens, Verdegem y De Marez 2010; Ginosar y Krispil 2015; Iosifidis 2011; Jõesaar 2011; Moe 2010; Psychogiopoulou 2013). Si bien algunos estudios previos han analizado la percepción de las audiencias relacionada con el estatus de RSP (Horsti y Hultén 2011; López Olano 2017), prácticamente cualquier estudio considera la opinión pública sobre los contenidos de RSP, la estructura de la programación y la variedad o calidad. Además, con respecto a la calidad de RSP, los artículos incluidos en esta revisión la consideran una de las primeras obligaciones y características de RSP, especialmente en Europa, pero aún se requiere una definición clara de las características y elementos principales que constituyen contenidos o servicios de alta calidad. Las investigaciones futuras deberían pasar al análisis de los puntos de vista de los críticos y el público con respecto a los temas, géneros y mensajes del programa, ya que la audiencia objetivo de la RSP incluye a los ciudadanos y no a los competidores, las partes interesadas o las instituciones. Por lo tanto, las preguntas de investigación futuras de RSP deberían ampliar sus muestras representativas, 
que incluyan no solo a productores y otros profesionales de los medios, sino también a espectadores y consumidores para proporcionar una amplia representación de todos los agentes involucrados y valorar el contenido del programa de RSP.

\subsection{Gestión de redes sociales en diferentes contextos}

La investigación de RSP relacionada con las estrategias digitales y multiplataforma todavía se basa profundamente en el caso de la BBC (D'Arma 2018; Ejbye Sørensen 2013; Goddard 2017; Ramsey 2018; Starks 2011), porque es la emisora pública más exitosa e internacional, dejando la pregunta sobre la adopción de estrategias y servicios en línea para otras emisoras públicas. La literatura existente ha demostrado que la BBC es la principal emisora pública que ha tenido éxito en el entorno digital gracias a su modelo mixto, asociación con emisoras comerciales y estrategia de marca. Sin embargo, pocos artículos consideran las técnicas empleadas por otros servicios o canales públicos; Las RSP de otras naciones solo se mencionan en relación con sus dificultades y estrategias fallidas, pero sin ahondar en sus causas o posibles alternativas. Esta perspectiva cerrada sobre los formatos en línea y las plataformas de redes sociales impide que la investigación de RSP descubra formas eficientes de gestionar los desafíos tecnológicos y digitales, porque — según Ayish (2010) y Marko (2015) —las necesidades y restricciones de una RSP difieren de una nación a otra, ya que las características políticas, sociales y culturales siguen siendo dominantes. De manera concisa, la investigación futura debería profundizar en el panorama digital, los servicios multiplataforma y los sitios de redes sociales, ya que este entorno está en constante y rápida evolución.

\subsection{Mejora del análisis cultural y artístico}

Aunque la educación y la cultura son dos de las principales obligaciones de la RSP (Esser \& Majbritt Jensen 2015; Grummel 2009; Pajala 2010; Shepperd 2014), se debe centrar la atención en la cultura artística e internacional. Estudios anteriores sugieren que los valores culturales y educativos se adaptan mejor a los intereses políticos y democráticos (Huntsberger 2014; Pajala 2010; Shepperd 2014; Steemers y D'Arma 2012); de hecho, en algunos estudios, el término “cultura" se refiere a la identidad nacional o local (Debrett 2009; Flew 2009; Spasovska e Imre 2015). Esto implica una falta de análisis cultural en un sentido amplio y general. Por lo tanto, la investigación futura de RSP debería considerar una definición más amplia y precisa de "cultura". Además, el valor real que ofrecen las RSP a través de programas culturales y educativos de alta calidad debe buscarse analizando el contenido del programa en relación con la identidad nacional, los valores democráticos y la información política, así como contemplando otras formas artísticas y culturales-incluidas las artes escénicas, el cine, o la música-que faltan en la investigación actual.

\section{Conclusiones}

El análisis de contenido sugiere que la investigación prototípica de la RSP es empírica, basada en enfoques cualitativos (estudios de caso), realizada en diferentes países, pero concentrada principalmente en el escenario europeo, y basada en datos provenientes de una exploración de las políticas y el marco regulatorio de la RSP. Además, los resultados del análisis temático sugieren que la corriente de investigación más sólida se basa en los desafíos y dificultades de la RSP que surgen del desarrollo tecnológico y digital, como la competencia y los incrementos de privatización y las luchas por financiamiento. Las sugerencias para investigaciones futuras deben hacer especial hincapié en las posibles soluciones y estrategias para gestionar los obstáculos de la RSP actual. Además, un nuevo análisis de las estrategias existentes adoptadas por algunas emisoras, como la BBC, así como casos fallidos, para determinar errores y causas de la inestabilidad actual para identificar pistas como base para posibles soluciones. Más allá de la controvertida situación, futuros estudios también podrían 
considerar incluir críticas y percepciones de espectadores reales para analizar rigurosamente la calidad y características de los contenidos públicos. Por último, la línea de investigación de RSP debería considerar incluir otros valores artísticos y culturales, más allá del sentimiento y la identidad nacional y política.

\section{Referencias}

Ala Fosi, M. \& Lax, S. (2016). The Short Future of Public Broadcasting: Replacing Digital Terrestrial Television with Internet Protocol? International Communication Gazette, 78(4), pp.365 382. https://doi.org/10.1177/1748048516632171

Arriaza Ibarra, K. (2013). The Situation of National and Regional Public Television in Spain Public Media in the Crossroad. Nordicom Review, 34(1), pp.145 156. https://doi.org/10.2478/nor-20130048

Arriaza Ibarra, K. \& Nord, L. W. (2014) Public Service Media under Pressure: Comparing Government Policies in Spain and Sweden 2006 2012. Javnost-The Public, 21(1), pp.71 84. https://doi.org/10.1080/13183222.2014.11009140

Ayish, M. I. (2010). Arab State Broadcasting Systems in Transition the Promise of The Public Service Broadcasting Model. Middle East Journal of Culture and Communication, 3(1). https://doi.org/10.1163/187398609X12584657078448

Brink Lund, A. \& Edelvold Berg, C. (2009). Denmark, Sweden and Norway: Television Diversity by Duopolistic Competition and Co-Regulation. The International Communication Gazette, 33(6), pp.953 962. https://doi.org/10.1177/1748048508097928

Candel, R. S. (2011). Public Policy Best Practice in The Field of Digital Terrestrial Television: Lessons from Sweden And Spain. International Journal of Digital Television, 2(3), pp.297 321. https://doi.org/10.1386/Jdtv.2.3.297 1

Chan Chin, Y. (2012). Public Service Broadcasting, Public Interest and Individual Rights in China. Media, Culture \& Society, 34(7), pp.898 912. https://doi.org/10.1177/0163443712452700

Collins, R. (2011). Content online and the end of public media? The UK, a canary in the coal mine? Media, Culture \& Society, 33(8), pp.1202 12129. https://doi.org/10.1177/0163443711422459

Curran, J., Iyengar, S., Brink Lund, A. \& Salovaara Moring, I. (2009) Media System, Public Knowledge and Democracy. European Journal of Communication, 24(1), pp.5 26. https://doi.org/10.1177/0267323108098943

Cushion, S., Lewis, J. \& Ramsay, G. N. (2012). The Impact of Interventionist Regulation in Reshaping News Agendas: A Comparative Analysis of Public and Commercially Funded Television Journalism. Journalism, 13(7), pp.831 849. https://doi.org/10.1177/1464884911431536

D'Arma, A. (2018). The hollowing out of public service media: a constructivist institutionalist analysis of the commercialisation of BBC's in-house production. Media, Culture \& Society, 40(3), pp.432 448. https://doi.org/10.1177/0163443717713260 
D’Arma, A. \& Labio, A. (2017). Making a difference? Public service broadcasting, distinctiveness and children's provision in Italy and Spain. International Journal of Digital Television, 8(2), pp.183 199. https://doi.org/10.1386/jdtv.8.2.183 1

Dawes, S. (2014). Broadcasting and The Public Sphere: Problematising Citizens, Consumers and

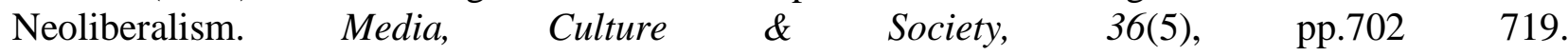
https://doi.org/10.1177/0163443714536842

Debrett, M. (2009). Riding the Wave: Public Service Television in The Multi-Platform Era. Media, Culture \& Society, 31(5), pp.807 827. https://doi.org/10.1177/0163443709339466

Denyer, D., \& Tranfield, D. (2006). Using qualitative research synthesis to build an actionable knowledge base. Management decision, 44(2), 213-227.

Donders, K. (2010). The Benefits of Introducing European Competition Principles into National Public Broadcasting Policy". Info. Digital Policy, Regulation and Governance, 12(6), pp.56 68. https://doi.org/10.1108/14636691011086044

Donders, K. \& Pauwels, C. (2010). The introduction of an ex ante evaluation for new media services: Is 'Europe' asking for it, or does public service broadcasting need it? International Journal of Media \& Cultural Politics, 6(2), pp.133 148. https://doi.org/10.1386/mcp.6.2.133 1

Donders, K. \& Raats, T. (2012). Analysing national practices after European state aid control: are multi-stakeholder negotiations beneficial for public service broadcasting? Media, Culture \& Society, 34(2), pp.162 180. https://doi.org/10.1177/0163443711430756

Donders, K. \& Raats, T. (2015). From public service media organisations to de-centralised public service for the media sector: a comparative analysis of opportunities and disadvantages. Javnost-The public, 22(2), pp.145 163. https://doi.org/10.1080/13183222.2015.1041227.

Donders, K., Van den Bulck, H. \& Raats, T. (2019) The politics of pleasing: a critical analysis of multistakeholderism in Public Service Media policies in Flanders. Media, Culture \& Society, 41(3), pp.347 366. https://doi.org/10.1177/0163443718782004 .

Ejbye Sørensen, I. (2013). Channels as content curators: Multiplatform strategies for documentary film and factual content in British public service broadcasting. European Journal of Communication, 29(1), pp.34 39. https://doi.org/10.1177/0267323113504856

Engelbert, J. \& Awad, I. (2014) Securitizing Cultural Diversity: Dutch Public Broadcasting in PostMulticultural and De-Pillarized Times. Global Media and Communication, 10(3), pp.261 274. https://doi.org/10.1177/1742766514552352

Enli, G. S. \& Ihlebæk, K. A. (2011) 'Dancing with The Audience': Administrating Vote-Ins in Public and Commercial Broadcasting. Media, Culture \& Society. https://doi.org/10.1177/0163443711412299

Esser, A. \& Majbritt Jensen, P. (2015). The Use of International Television Formats by Public Service Broadcasters in Australia, Denmark And Germany. International Communication Gazette, 77(4), pp.359 383. https://doi.org/10.1177/1748048514568766 
Evans, S. K. (2018). Making Sense of Innovation: Process, Product, And Storytelling Innovation in Public Service Broadcasting Organizations. Journalism Studies, 19(1), pp.4 24. https://doi.org/10.1080/1461670X.2016.1154446

Evens, T., Verdegem, P. \& De Marez, L. (2010). Balancing Public and Private Value for The Digital Television Era. Javnost-The Public, 17(1), pp. $37 \quad 54$. https://doi.org/10.1080/13183222.2010.11009025

Fernández Alonso, I., Bonet, M., Guimerà, J. A., Díez, M. \& Alborch, F. (2010). Spanish Public Broadcasting. Defining traits and future challenges following analogue television switch off. Observatorio (OBS*), 4(3). https://doi.org/10.15847/obsOBS432010351

Flew, T. (2009). The Special Broadcasting Service After 30 Years: Public Service Media and New Ways of Thinking About Media and Citizenship. Media International Australia, 133(1), pp.9 14. https://doi.org/10.1177/1329878X0913300103

Flynn, R. (2015). Public service broadcasting beyond public service broadcasters. International Journal of Digital Television, 6(2), pp.125 144. https://doi.org/10.1386/jdtv.6.2.125_1 .

García de Madariaga, J. M., Lamuedra Graván, M. \& Tucho Fernández, F. (2013). Challenges to public service news programmes in Spain: Professionals and viewers' discourses wavering between institutional reform and counter-reform. Journalism: Theory, Practice \& Criticism, 15(7), pp.908 925. https://doi.org/10.1177/1464884913508609

Ginosar, A. \& Krispil, O. (2015). Broadcasting Regulation and The Public Interest: Independent Versus Governmental Agencies. Journalism \& Mass Communication Quarterly, 93(4), pp.946 966. https://doi.org/10.1177/1077699015610066

Goddard, P. (2017). 'Distinctiveness' and the BBC: A New Battleground for Public Service Television? Media, Culture \& $\quad$ Society, $\quad 39(7), \quad$ pp.1089 1099. https://doi.org/10.1177/0163443717692787

Gómez García, Rodrigo (2009). Panorama internacional de los sistemas de radiodifusión de servicio público. Vectores del pluralismo democrático, la diversidad y la producción culturales. Revista $\begin{array}{lllll}\text { mexicana de ciencias políticas y } & \text { sociales, } & 51(206), & 157-175\end{array}$ http://www.scielo.org.mx/scielo.php?pid=S0185-19182009000200009\&script=sci_arttext

Grummel, B. (2009). The Educational Character of Public Service Broadcasting from Cultural Enrichment to Knowledge Society. European Journal of Communication, 24(3), pp.267 285. https://doi.org/10.1177/0267323109336756

Harrison, J. \& Woods, L. M. (2001). Defining European public service broadcasting. European journal of communication, 16(4), 477-504.

Herzog, C. \& Karppinen, K. (2014). Policy streams and public service media funding reforms in Germany and Finland. European Journal of Communication, 29(4), pp.416 432. https://doi.org/10.1177/0267323114530581 
Horsti, K. \& Hultén, G. (2011). Directing Diversity: Managing Cultural Diversity Media Policies in Finnish And Swedish Public Service Broadcasting. International Journal of Cultural Studies, 14(2), pp.209 227. https://doi.org/10.1177/1367877910382180

Huntsberger, M. W. (2014). Attempting an Affirmative Approach to American Broadcasting: Ideology, Politics, And the Public Telecommunications Facilities Program. Journalism \& Mass Communication Quarterly, 91(4), pp.756 771. https://doi.org/10.1177/1077699014550089

Iosifidis, P. (2011). Growing pains? The transition to digital television in Europe. European Journal of Communication, 26(1), pp.3 17. https://doi.org/10.1177/0267323110394562

Jacobs, L., Meeusen, C. \& d'Haenens, L. (2016) News Coverage and Attitudes on Immigration: Public and Commercial Television News Compared. European Journal of Communication, 31(6), pp.642 660. https://doi.org/10.1177/0267323116669456

Jõesaar, A. (2011). Different Ways, Same Outcome? Liberal Communication Policy and Development of Public Broadcasting. Trames, 15(1), pp.74 101. https://doi.org/10.3176/tr.2011.1.04

Johnson, K. (2013). From brand congruence to the 'virtuous circle': branding and the commercialization of public service broadcasting. Media, Culture \& Society, 35(3), pp.314 331. https://doi.org/10.1177/0163443712472088

Just, N., Latzer, M. \& Saurwein, F. (2012). Public service broadcasting put to test: Ex post control of online services. International Journal of Media \& Cultural Politics, 8(1), pp.51 65. https://doi.org/10.1386/macp.8.1.51_1

Kant, T. (2014). Giving the "Viewer" a Voice? Situating the Individual in Relation to Personalization, Narrowcasting and Public Service Broadcasting. Journal of Broadcasting and Electronic Media, 58(3), pp.381 399. https://doi.org/10.1080/08838151.2014.935851.

Keinonen, H. \& Klein Shagrir, O. (2017). From Public Service Broadcasting to Soci(et) al TV Producers' Perceptions of Interactivity and Audience Participation in Finland and Israel. Nordicom Review, 38(1), pp.65 79. https://doi.org/10.1515/nor-2016-0037

Kolmer, C. \& Semetko, H. A. (2010). International Television News: Germany Compared. Journalism Studies, 11(5), pp.700 717. https://doi.org/10.1080/1461670x.2010.503020

Larrondo, A., Larrañaga, J., Meso, K. \& Agirreazkuenaga, I. (2012). The Convergence Process in Public Audio-visual Groups: The Case of Basque Public Radio Television (Eitb). Journalism Practice, 6(5-6), pp.788 797. https://doi.org/10.1080/17512786.2012.667282

Larrondo, A., Domingo, D., Erdal, I. J., Masip, P. \& Van den Bulck, H. (2016). Opportunities and Limitations of Newsroom Convergence: A Comparative Study on European Public Service Broadcasting Organisations. Journalism Studies, $17(3), \quad$ pp.277 300. https://doi.org/10.1080/1461670X.2014.977611

Larsen, H. (2014). The Legitimacy of Public Service Broadcasting in the 21st Century the Case of Scandinavia. Nordicom Review, 35(2), pp.65 76. https://doi.org/10.2478/nor-2014-0015 
López Olano, C. (2017). The Model for Public Television and the Young Audience's Expectations. Differences Between Great Britain and Spain in the Perception of Qualities and Obligations. El Profesional de la Información, 26(4), pp.1699 2407. https://doi.org/10.3145/Epi.2017.Jul.15

Mangani, A. \& Tarrini, E. (2018). Social Pluralism in Public and Private Television Broadcasting. Javnost-The Public, 25(3), pp.282 297. https://doi.org/10.1080/13183222.2018.1463044

Marko, D. (2015). The role of media assistance in the establishment of public service broadcasting in Serbia. International Journal of Digital Television, 6(3), pp.293 309. https://doi.org/10.1386/jdtv.6.3.293_1

Michalis, M. (2016). Radio spectrum battles: Television broadcast vs wireless broadband and the future of PSB. International Journal of Digital Television, 7(3), pp.347 362. https://doi.org/10.1386/jdtv.7.3.347 1

Millanga, A. K. (2014). Mobile Phones and Participatory Communication for Poverty Eradication on Public Service Broadcasting: The Case of Tanzania Broadcasting Corporation (Tbc). Mobile, Media \& Communication, 2(3), pp.281 297. https://doi.org/10.1177/2050157914533695

Mjøs, O. J. (2011). Marriage of convenience? Public service broadcasters' cross-national partnerships in factual television. International Communication Gazette, 73(3), pp.181 197. https://doi.org/10.1177/1748048510393652

Moe, H. (2010). Governing Public Service Broadcasting: "Public Value Tests" In Different National Contexts. Communication, Culture \& Critique, 3(2), pp.207 223. https://doi.org/10.1111/J.1753 9137.2010.01067.X

Moe, H. (2013). Public Service Broadcasting and Social Networking Sites: The Norwegian Broadcasting Corporation on Facebook. Media International Australia, 146(1), pp.114 122. https://doi.org/10.1177/1329878X1314600115

Pajala, M. (2010). Television as An Archive of Memories? Cultural Memory and Its Limits on The Finnish Public Service Broadcaster's Online Archive. Critical Studies In Television, 5(2), pp.133 145. https://doi.org/10.7227/CST.5.2.16

Psychogiopoulou, E. (2013). Media Policy-Making in Greece: Lessons from Digital Terrestrial Television and The Restructuring of Public Service Broadcasting. International Journal of Media \& Cultural Politics, 9(2), pp.133 152. https://doi.org/10.1386/Macp.9.2.133_1

Puijk, R. (2015) Slow Television A Successful Innovation in Public Service Broadcasting. Nordicom Review, 36(1), pp.95 108. https://doi.org/10.1515/nor-2015-0008

Radovic, I. \& Luther, C. A. (2012). From State Controlled to Public Service Broadcasting: Signs of Change in Serbia's RTs Television Newscasts 1989-2009. Journal of Broadcasting \& Electronic Media, 56(2), pp.245 260. https://doi.org/10.1080/08838151.2012.678517

Ramsey, P. (2016). Commercial Public Service Broadcasting in the United Kingdom: Public Service Television, Regulation, and the Market. Television \& New Media, 18(7), pp.639 654. https://doi.org/10.1177/1527476416677113 
Ramsey, P. (2018). 'It Could Redefine Public Service Broadcasting in The Digital Age' Assessing the Rationale for Moving BBC Three Online. Convergence, 24(2), pp.152 167. https://doi.org/10.1177/1354856516659001

Scannell, P. (2005). Public service broadcasting: the history of a concept. In Understanding television (pp. 20-38). Routledge.

Schwarz, J. A. (2016). Public Service Broadcasting and Data-Driven Personalization: A View from Sweden. Television \& New Media, 17(2), pp.124 141. https://doi.org/10.1177/1527476415616193

Shamseer et al. (2015). Preferred reporting items for systematic review and meta-analysis protocols (PRISMA-P) 2015: elaboration and explanation. BMJ, 349(jan2015), g.7647 g7647.

Shepperd, J. (2014). Infrastructure in The Air: The Office of Education and The Development of Public Broadcasting in The United States, 1934-1944. Critical Studies in Media Communication, 31(3), pp.230 243. https://doi.org/10.1080/15295036.2014.889320

Sjøvaag, H., Moe, H. \& Stavelin, E. (2012). Public Service News on The Web: A Large-Scale Content Analysis of The Norwegian Broadcasting Corporation's Online News. Journalism Studies, 13(1), pp.90 106. https://doi.org/10.1080/1461670X.2011.578940

Sjøvaag, H., Stavelin E. \& Moe, H. (2015). Continuity and Change in Public Service News Online: A Longitudinal Analysis of The Norwegian Broadcasting Corporation. Journalism Studies, 17(8), pp952 970. https://doi.org/10.1080/1461670X.2015.1022204

Sjøvaag, H., Pedersen, T. A. \& Owren, T. (2019). Is Public Service Broadcasting A Threat to Commercial Media? Media, Culture \& Society, 41(6), pp.808 827. https://doi.org/10.1177/0163443718818354

Smith, L. K. (2009). Consolidation and News Content: How Broadcast Ownership Policy Impacts Local Television News and The Public Interests. Journalism \& Communication Monographs, 10(4), pp.387 45. https://doi.org/10.1177/152263790901000403

Spasovska, K. \& Imre, I. (2015). Transformation of The Public Broadcasting Systems in Croatia And Macedonia As Indicators of Democratic Transformation. International Journal of Digital Television, 6(3), pp.275 292. https://doi.org/10.1386/Jdtv.6.3.275_1

Starks, M. (2011). Can the BBC live to be 100? Public service broadcasting after digital switchover. International Journal of Digital Television, $\quad 2(2), \quad$ pp.181 200. https://doi.org/10.1386/jdtv.2.2.181 1

Steiner, M., Magin, M. \& Stark, B. (2019). Uneasy Bedfellows: Comparing the Diversity of Germany Public Service News on Television and on Facebook. Digital Journalism, 7 (1), pp.100_123. https://doi.org/10.1080/21670811.2017.1412800

Steemers, J. \& D'Arma, A. (2012). Evaluating and regulating the role of public broadcasters in the children's media ecology: The case of home-grown television content. International Journal of Media \& Cultural Politics, 8(1), pp.67 85. https://doi.org/10.1386/macp.8.1.67_1 
Stollfuß, S. (2018). Is This Social Tv 3.0? On Funk and Social Media Policy in German Public Post Television Content Production. Television \& New Media,00(0), pp.1 16. https://doi.org/10.1177/1527476418755514

Storr, J. (2011). The Disintegration of The State Model in The English-Speaking Caribbean: Restructuring and Redefining Public Service Broadcasting. International Communication Gazette, 73(7), pp.553 572. https://doi.org/10.1177/1748048511417155

Taylor, G. (2016). Dismantling the Public Airwaves: Shifting Canadian Public Broadcasting to An Online Service. The International Communication Gazette, 78(4), pp.349 364. https://doi.org/10.1177/1748048516632169

Van den Bulck, H. \& Donders, K. (2014) Of discourses, stakeholders and advocacy coalitions in media policy: Tracing negotiations towards the new management contract of Flemish public broadcaster VRT. European Journal of Communication, $29(1), \quad$ pp.83 99. https://doi.org/10.1177/0267323113509362

Van den Bulck, H. \& Moe, H. (2012). To test or not to test: Comparing the development of ex ante public service media assessments in Flanders and Norway. International Journal of Media \& Cultural Politics, 8(1), pp.31 49. https://doi.org/10.1386/macp.8.1.31_1

Van Dijck, J. \& Poell, T. (2015). Making Public Television Social? Public Service Broadcasting and the Challenges of Social Media. Television \& New Media, 16(2), pp.148 164. https://doi.org/10.1177/1527476414527136.

Vanhaeght, A. S. \& Donders, K. (2016). Moving Beyond the Borders of Top-Down Broadcasting: An Analysis of Younger Users' Participation in Public Service Media. Television \& New Media, 17(4), pp.291 307. https://doi.org/10.1177/1527476415595871

Värk, A. \& Kindsiko, E. (2019). Knowing in Journalistic Practice: Ethnography in A Public Broadcasting Company. Journalism Practice, $13(3), \quad$ pp.298 313. https://doi.org/10.1080/17512786.2018.1424022

\section{AUTORES}

\section{Tania Lestón-Huerta}

Tania Lestón-Huerta es Alumna de Maestría en Ciencias de la Comunicación en la Universidad Carlos III de Madrid y sus principales intereses son las plataformas de nuevos medios y la sociología de las ciencias de la comunicación. Su actividad de investigación más reciente se ocupa de los sitios de redes sociales y los patrones de comportamiento de los usuarios.

tanialh96@gmail.com

Índice H: 0

Orcid ID: https://orcid.org/0000-0002-1727-357X

\section{Manuel Goyanes}

Manuel Goyanes, Doctor, Manuel Goyanes, Doctor, es profesor en la Universidad Carlos III de Madrid y sus principales intereses son la gestión de medios y la sociología de las ciencias de la comunicación. Ha escrito sobre liderazgo, sobrecarga de noticias y modelos de negocio. Es autor de Desafio a la Investigación Estándar en Comunicación. Crítica y Alternativas, Editorial UOC. 
mgoyanes@hum.uc3m.es

Índice H: 13

Orcid ID: https://orcid.org/0000-0001-6537-9777

Google Scholar: https://scholar.google.com/citations?hl=es\&user=ouvI-1QAAAAJ

ResearchGate: https://www.researchgate.net/profile/Manuel Goyanes

Scopus ID: https://www.scopus.com/authid/detail.uri?authorId=49863192400

\section{Barbara Mazza}

Barbara Mazza, profesora asociada y presidenta de la maestría en Organización y Marketing para la Comunicación Empresarial de la Universidad Sapienza. Es la coordinadora local de varios proyectos de investigación a nivel nacional e internacional, y miembro de IRNIST, Red Internacional de Investigación en Turismo Deportivo. La mayoría de sus publicaciones recientes tratan sobre temas de comunicación empresarial.

barbara.mazza@uniroma1.it

Índice H: 9

Orcid ID: https://orcid.org/0000-0001-5981-8729

Google Scholar: https://scholar.google.com/citations?hl=es\&user=J8ZW0-EAAAAJ

ResearchGate: https://www.researchgate.net/profile/Barbara_Mazza6

Scopus ID: https://www.scopus.com/authid/detail.uri?authorId=57202984223 